\title{
EVALUASI SIFAT FISIK SEDIAAN SALEP MINYAK CENGKEH (SYZIGIUM AROMATICUM) DALAM BASIS LARUT AIR
}

\author{
Rani Prabandari' ${ }^{1)}$, Adita Silvia ${ }^{2)}$ \\ ${ }^{1), 2)}$ Program Studi Farmasi Sekolah Tinggi Ilmu Kesehatan Harapan Bangsa Purwokerto \\ ${ }^{1)}$ raniprabandario@shb.ac.id ${ }^{2}$ aditasilvia@shb.ac.id
}

\begin{abstract}
Abstrak
Minyak atsiri bunga cengkeh (Syzygium aromaticum) dengan senyawa aktif eugenol telah banyak diteliti dan diketahui berkhasiat sebagai antiinflamasi, dan penelitian lanjutan terkait formulasinya terus dilakukan. Formula yang dikembangkan pada penelitian ini adalah bentuk sediaan topikal salep dengan menggunakan basis larut air (enhancer asam oleat dan propilen glikol). Penelitian ini bertujuan untuk mengetahui sifat fisik dan daya iritasi dari sediaan salep minyak atsiri bunga cengkeh (MABC) jika digunakan basis hidrokarbon. Salep dibuat dengan metode peleburan dengan konsentrasi MABC 5\% (F1), $10 \%$ (FII) dan 15\% (FIII). Salep dari ketiga formula ini kemudian dievaluasi sifat fisiknya, meliputi daya sebar, daya lekat dan $\mathrm{pH}$. Hasil uji statistik dengan uji LSD menunjukkan terdapat perbedaan yang signifikan antar formula. Semakin tinggi konsentrasi MABC, menyebabkan makin besar daya sebar (p0,05). Hasil uji iritasi Simplex Lattice Design menunjukkan pula bahwa salep basis larut air dengan konsentrasi MABC 5\%, $10 \%$ dan $15 \%$ tidak menimbulkan efek iritasi.
\end{abstract}

Kata kunci : Syzygium aromaticum, basis salep larut air, antiinflamasi.

\begin{abstract}
The clove flower essential oil (Syzygium aromaticum) with the active compound eugenol has been widely investigated and is known to be efficacious as an anti-inflammatory agent, and further research on its formulation continues. The formula developed in this study was a topical ointment dosage form using a water soluble base (oleic acid enhancer and propylene glycol). This study aims to determine the physical and irritant properties of the clove flower essential oil ointment (MABC) if a hydrocarbon base is used. The ointment is made by the smelting method with a concentration of 5\% (F1), 10\% (FII) and 15\% (FIII). The ointments of the three formulas were then evaluated for their physical properties, including dispersion, adhesion and $\mathrm{pH}$. The results of statistical tests with the LSD test showed that there were significant differences between formulas. The higher the concentration of MABC, the greater the spread (p0.05). The results of the Simplex Lattice Design irritation test also show that water-soluble base ointment with a concentration of 5\%, $10 \%$ and $15 \%$ MABC does not cause an irritating effect.
\end{abstract}

Keywords: Syzygium aromaticum, base of water soluble ointment, anti-inflammatory. 


\section{PENDAHULUAN}

Minyak cengkeh merupakan minyak atsiri yang berasal dari tanaman cengkeh (Syzygium aromaticum) yang memiliki aktivitas biologis karena mengandung senyawa eugenol dan dikenal memiliki sifat farmakologi seperti hipotermia, antioksidan, anestesi lokal dan antiinflamasi. Penelitian telah menunjukkan bahwa eugenol menekan sinyal TNF $\alpha$ dan ekspresi COX-2, yang menunjukkan potensinya sebagai agen anti-inflamasi (Chainy dkk., 2000). Berdasarkan potensi minyak atsiri bunga cengkeh dengan bahan aktif eugenol sebagai anti inflamasi, maka perlu dikembangkan bentuk sediaan yang acceptable dan dapat diterima dengan baik oleh masyarakat luas. Pengembangan formula terhadap minyak atsiri bunga cengkeh (MABC) terus dilakukan. Salah satu cara yang dapat dilakukan untuk mengembangkan formula dari MABC yaitu dengan menambahkan suatu enhancer pada formulasi sediaan.

Metode yang digunakan pada penelitian ini untuk mengetahui komposisi optimum asam oleat dan propilen glikol adalah metode Simplex Lattice Design. Metode Simplex Lattice Design merupakan metode untuk menentukan proporsi komponen teroptimum yang disesuaikan dengan variabel atau respon yang telah ditentukan. Metode Simplex Lattice Design juga merupakan salah satu dari beberapa teknik yang digunakan dalam prosedur optimasi formulasi yang berguna dalam perencanaan sediaan obat (Bolton, 1997).

Berdasarkan latar belakang tersebut, peneliti ingin melihat aktivitas anti inflamasi dari sediaan salep basis larut air Minyak Atsiri Bunga Cengkeh (MABC) (Syzygium aromaticum) yang telah terstandarisasi dengan penambahan enhancer. Penelitian ini diharapkan dapat memberikan efek sebagai antiinflamasi namun tidak memberikan efek iritasi.

\section{METODOLOGI}

Penelitian ini dilaksanakan di Laboratorium Kimia Farmasi, Laboratorium Teknologi Farmasi Program Studi S1 Farmasi Sekolah Tinggi Ilmu Kesehatan Harapan Bangsa Purwokerto Bahan yang digunakan adalah minyak atsiri bunga cengkeh yang didapat dari Pasar Pamijen Baturaden, Polietilen glikol (PEG) 400 (derajat farmasetis) dan PEG 4000 (derajat farmasetis), crotton oil (Sigma), mencit jantan galur BALB/c umur 2-3 bulan dengan berat badan 20-30 g, perontok rambut (Veet) dan mikroskop (Olympus).

Penelitian ini merupakan penelitian eksperimental dengan membandingkan 
beberapa perbandingan konsentrasi enhancer asam oleat dan propilen glikol pada sediaan salep basis serap minyak atsiri bunga cengkeh terhadap uji anti inflamasi berdasarkan metode Simplex Lattice design, dan dilakukan evaluasi sediaan yang meliputi uji transport eugenol dalam minyak atsiri melewati membran kulit, uji sifat fisik sediaan, dan uji daya iritasi.

Evaluasi Daya Iritasi Salep Basis Larut Air:

Uji Daya Sebar : Salep yang sudah ditimbang sebesar 0,5 gr diletakkan diatas kaca bulat yang berdiameter $15 \mathrm{~cm}$, lalu kaca lainnya diletakkan di atasnya dan dibiarkan selama 1 menit. Diameter penyebaran salep diukur. Setelahnya, ditambahkan $100 \mathrm{~g}$ beban tambahan dan didiamkan selama 1 menit lalu diukur diameter yang konstan (Naibaho dkk., 2013).

Uji Daya Lekat : Salep yang sudah ditimbang sebesar 0,25 g diletakkan di atas gelas obyek yang telah ditentukan luasnya, lalu diletakkan gelas obyek yang lain di atas salep tersebut dan ditekan dengan beban 1 $\mathrm{kg}$ selama 5 menit. Selanjutnya dipasang gelas obyek pada alat tes. Dilepas beban seberat 80 gram,dan dicatat waktunya hingga kedua gelas obyek tersebut terlepas (Naibaho dkk., 2013).
Uji $\mathrm{Ph}$ : Salep yang sudah ditimbang sebesar 0,5 g dilarutkan dengan $5 \mathrm{~mL}$ aquades, kemudian di cek $\mathrm{pH}$ larutannya (Naibaho dkk., 2013).

\section{HASIL DAN PEMBAHASAN}

Metode pembuatan formula salep basis larut air minyak atsiri bunga cengkeh menggunakan metode peleburan. Salep dibuat dengan memanaskan PEG 400 dan PEG 4000 kemudian diaduk sampai terbentuk massa yang kental dan homogen lalu dimasukkan enhancer (asam oleat dan propilen glikol) dan diaduk sampai homogen. Minyak atsiri ditambahkan ketika sudah dingin kemudian dicampur hingga homogen. Pembuatan salep minyak atsiri bunga cengkeh dalam basis larut air dilakukan dengan cara sebagai berikut: konsentrasi minyak atsiri bunga cengkeh yang digunakan dalam pembuatan salep basis larut air adalah konsentrasi sebesar $5 \%, 10 \%, 15 \%$. Selanjutnya dalam formula tersebut ditambahkan enhancer asam oleat dan propilen glikol yang komposisi optimumnya telah ditentukan berdasarkan metode Simplex Lattice Design seperti yang disajikan pada Tabel 1. 
Tabel 1. Formula sediaan salep basis larut air minyak atsiri bunga cen dengan penambahan enhancer asam oleat dan propilen glikol

\begin{tabular}{llll} 
Bahan & Formula I (\%) & Formula II (\%) & Formula III (\%) \\
\hline MABC Terstandar & 5 & 10 & 15 \\
Asam oleat & 85,5 & 81 & 76,5 \\
Propilen glikol & 0 & 5 & 10 \\
\hline *MABC : Minyak Atsiri Bunga Cengkeh & \\
Keterangan : & $\begin{array}{l}\text { Formula I (FI) formula dengan } \\
\text { danpropilen glikol 0\% }\end{array}$ & \\
& Formula II (FII) formula dengan komposisi asam oleat $50 \%$ dan \\
& propilen glikol 50\% \\
& Formula III (FIII) formula dengan komposisi asam oleat $0 \%$ dan \\
& propilen glikol 100\%
\end{tabular}

Penelitian ini menggunakan 6 ekor dicukur, lalu ditutup dengan kasa steril marmut jantan dengan rata-rata usia 2 kemudian direkatkan dengan plester. bulan. Rambut pada bagian punggung Setelah 24 jam, plester dan perban dibuka marmut dicukur sampai bersih. Punggung dan dibiarkan selama 1 jam, lalu diamati. marmut lalu dibagi menjadi 6 bagian yang Setelah diamati, bagian tersebut ditutup berbentuk bujur sangkar, yang akan kembali dengan plester yang sama dan diberikan perlakuan sediaan salep dengan dilakukan pengamatan kembali setelah 72 konsentrasi 5\%, 10\%, 15\%, basis, kontrol jam (Irsan dkk, 2013). Selanjutnya untuk sakit dan kontrol sehat. Masing-masing setiap keadaan kulit diberi nilai sebagai sampel iritan sebanyak 0,5 g dioleskan pada berikut (Draize, 1959):

bagian punggung marmut yang telah

Tabel 2. $\quad$ Nilai kondisi kulit

\begin{tabular}{lc}
\hline \multicolumn{1}{c}{ Kondisi Kulit } & Nilai \\
\hline Tidak ada eritema & 0 \\
Eritema sangat ringan & 1 \\
Eritema ringan & 2 \\
Eritema sedang & 3 \\
Eritema berat & 4 \\
Tidak ada edema & 0 \\
Edema sangat ringan & 1 \\
Edema ringan & 2 \\
Edema sedang & 3 \\
Edema berat & 4 \\
\hline
\end{tabular}


Indeks iritasi dihitung dengan cara menjumlahkan nilai dari setiap marmut percobaan setelah 24 jam dan 72 jam pemberiaan sampel iritan, kemudian dibagi

4. Penilaian iritasinya sebagai berikut:

$0,00=$ Tidak mengiritasi

$0,04-0,99=$ Sedikit mengiritasi

$1,00-2,99=$ Iritasi ringan

$3,00-5,99=$ Iritasi sedang

$6,00-8,0=$ Iritasi berat.

Uji daya sebar pada salep dilakukan untuk melihat kemampuan sediaan menyebar pada kulit, dimana suatu basis salep sebaiknya memiliki daya sebar yang baik untuk menjamin pemberian bahan obat yang baik (Naibaho dkk., 2013). Hasil uji daya sebar disajikan pada Gambar 1. Hasil uji menunjukkan bahwa peningkatan konsentrasi MABC dalam sediaan salep menurunkan konsistensi dari salep, sehingga luas area penyebaran salep meningkat. Namun demikian daya sebar salep basis larut air belum memenuhi syarat daya sebar untuk sediaan topikal yaitu sekitar 5-7 cm (Ulaen dkk., 2012). Hasil uji ini sesuai dengan hasil penelitian Sari dkk (2015) yang menunjukkan bahwa peningkatan konsentrasi minyak atsiri bunga cengkeh dalam basis emulgel menyebabkan peningkatan daya sebar.

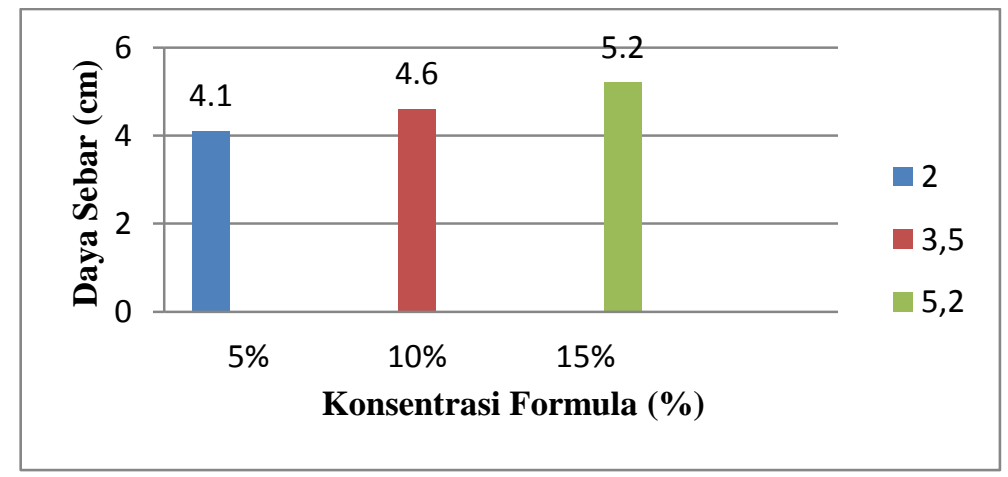

Gambar 1. Diagram Daya Sebar Salep Minyak Atsiri Bunga Cengkeh pada Basis larut air dengan Konsentrasi 5\% (FI), 10\% (FII), dan 15\% (FIII)

Hasil uji daya sebar ini lalu dianalisa menggunakan uji anova dengan taraf kepercayaan 95\%. Hasil uji statistik menunjukkan data uji daya sebar sedangkan antara konsentrasi 5\%, 10\%, dan terdistribusi normal dan homogen $(\mathrm{p}>0,05)$. 15\% menunjukkan perbedaan yang Setelah itu dilakukan uji LSD untuk melihat signifikan $(\mathrm{p}<0,05)$. perbedaan antara kelompok konsentrasi minyak atsiri. Hasil uji LSD menunjukkan tidak ada perbedaan signifikan antara konsentrasi $5 \%$ dan $10 \% \quad(\mathrm{p}>0,05)$, 
Uji daya lekat pada salep dilakukan mempengaruhi kemampuan penetrasi salep untuk melihat kemampuan salep melekat ke dalam kulit untuk menimbulkan efek. pada kulit, dimana hal ini dapat Hasil uji daya lekat disajikan berikut ini.

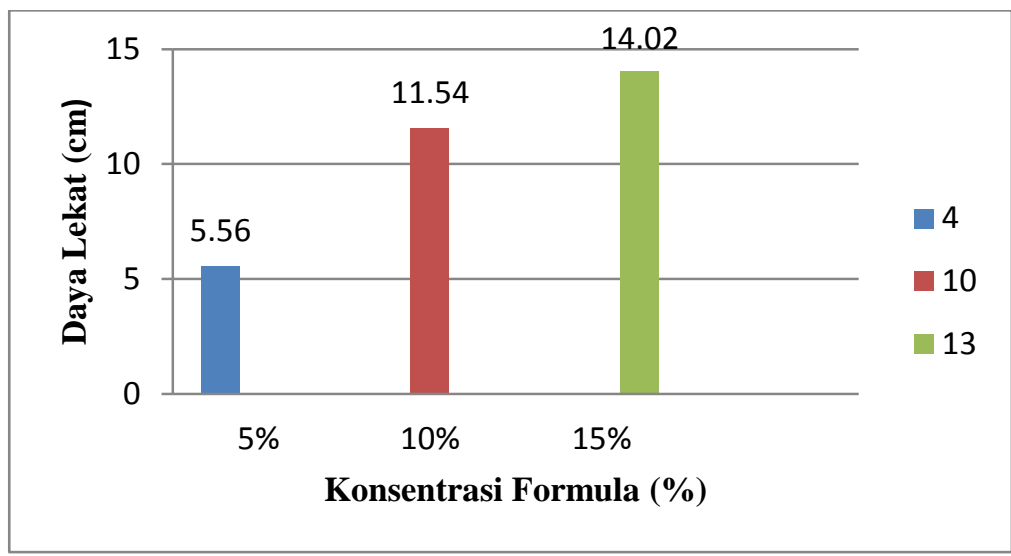

Gambar 2. Diagram Daya Lekat Salep Minyak Atsiri Bunga Cengkeh pada Basis Hidrokarbon dengan Konsentrasi 5\% (FI), 10\% (FII), dan (FIII)

Hasil uji daya lekat menunjukkan konsentrasi minyak atsiri memenuhi bahwa peningkatan konsentrasi MABC persyaratan daya lekat.

dalam sediaan salep meningkatkan

Hasil uji daya lekat ini lalu dianalisis kemampuan melekat dari salep, sehingga menggunakan anova dengan taraf waktu daya lekat salep meningkat, berkisar kepercayaan 95\%. Hasil uji statistik antara 6-14 menit. Hal ini dipengaruhi oleh menunjukkan bahwa data uji daya lekat basis salep yang bersifat lemak, sehingga terdistribusi normal dan homogen ( $p>0,05)$. ikatan dengan minyak atsiri bunga cengkeh Setelah itu dilakukan uji SLD untuk melihat kuat, yang memungkinkan untuk waktu perbedaan antara kelompok konsentrasi kontak sediaan dengan kulit lebih lama, minyak atsiri. Hasil uji SLD menunjukkan sehingga penetrasi salep dapat tidak ada perbedaan signifikan antara menghasilkan efek yang lebih baik. Syarat konsentrasi 5\% dan 10\% (p>0,05) serta untuk daya lekat pada sediaan topikal konsentrasi $10 \%$ dan $15 \%$, tetapi antara adalah tidak kurang dari 4 detik (Ulaen konsentrasi 5\% dengan 15\% menunjukkan dkk., 2012). Hal ini menunjukkan sediaan perbedaan yang signifikan $(\mathrm{p}<0,05)$. salep basis hidrokarbon dengan berbagai

Pengujian sifat fisik selanjutnya adalah pengujian $\mathrm{pH}$. Pengujian $\mathrm{pH}$ 
dilakukan untuk melihat $\mathrm{pH}$ salep apakah berada pada rentang $\mathrm{pH}$ normal kulit yaitu 4,5 - 7. Jika $\mathrm{pH}$ terlalu basa dapat mengakibatkan kulit kering, sedangkan jika
$\mathrm{pH}$ kulit terlalu asam dapat memicu terjadinya iritasi kulit (Mappa dkk.,2013; Swastika dkk., 2013).

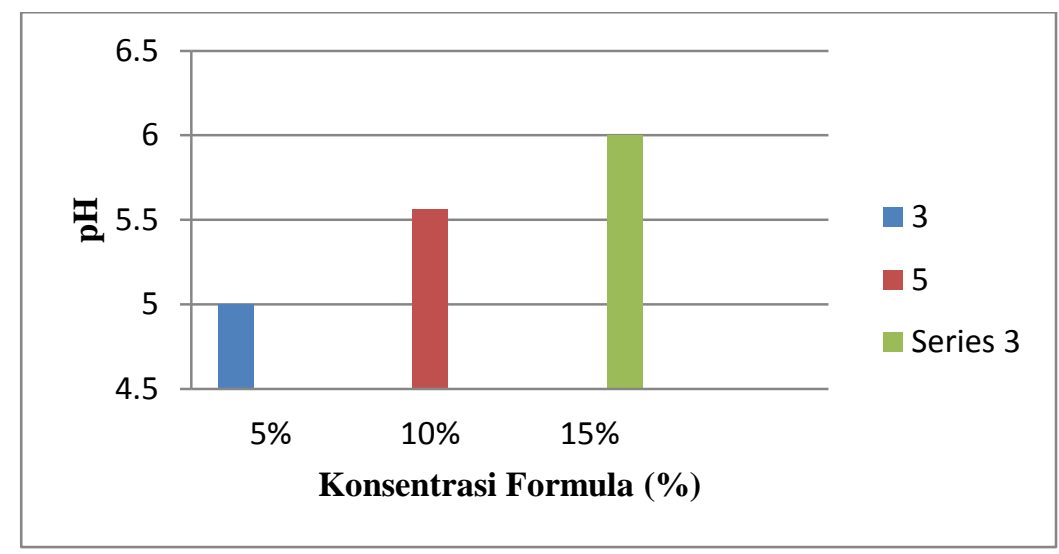

Gambar 3. Diagram pH Salep Minyak Atsiri Bunga Cengkeh pada Basis Hidrokarbon dengan Konsentrasi 5\% (FI), 10\% (FII), dan 15\% (FIII)

Hasil pengujian menunjukkan $\mathrm{pH}$ sediaan salep basis larut air minyak atsiri bunga cengkeh berada di antara $\mathrm{pH} 5-6$. Hal ini sudah masuk dalam rentang $\mathrm{pH}$ yang disyaratkan untuk sediaan topikal. Hasil uji $\mathrm{pH}$ ini lalu dianalisis menggunakan anova dengan taraf kepercayaan 95\%. Hasil uji statistik menunjukkan bahwa data uji $\mathrm{pH}$ terdistribusi normal $(\mathrm{p}>0,05)$ namun tidak homogen $(\mathrm{p} 0,05)$ yang menunjukkan tiap konsentrasi memiliki nilai $\mathrm{pH}$ yang aman bagi tubuh karena berada pada kisaran $\mathrm{pH}$ kulit normal. Pengamatan daya iritasi salep basis larut air dilakukan untuk mengetahui apakah bahan-bahan yang digunakan pada formulasi salep memiliki sifat mengiritasi pada kulit.

\section{KESIMPULAN}

Sifat fisik sediaan salep MABC yang meliputi daya sebar, daya lekat dan $\mathrm{pH}$ tidak memiliki perbedaan yang signifikan antar masing-masing formula. Sediaan salep MABC tidak memiliki efek iritasi pada dosis 5\%,10\% da 15\% pada hewan uji mencit.

\section{SARAN}

Perlu dilakukan penelitian lebih lanjut tentang evaluasi pada toksisitas dari sediaan salep basis larut air sehingga bisa lebih optimal dalam mengobati inflamasi dan untuk mengevaluasi batas keamanannya jika digunakan dalam jangka panjang. 


\section{DAFTAR PUSTAKA}

Ashari, S. 1995. Hortikultura, Aspek Budidaya. Universitas Indonesia. Jakarta

Asmawati, N., Purwati P. dan HandayaniR. S.2015. Efektivitas Rebusan Seledri Dalam Menurunkan Tekanan Darah Pada Lansia Penderita Hipertensi Di Posyandu Lansia Kelurahan Pajar Bulan Kecamatan Way Tenong Lampung Barat. Jurnal Kesehatan. 4 (2): 130-136.

Badan Pengawas Obat dan Makanan Repoblik Indonesia. 2004. Volume I. BPOM RI. Jakarta.

Badan Pengawas Obat dan Makanan Repoblik Indonesia. 2008. Seledri sebagai Bahan Obat Alam.

Badan Standarisasi Nasional. 1992. SNI 012891-1992. Cara Uji Makanan dan Minuman. Jakarta.

Badan Standarisasi Nasional. 2013. SNI 013544: 2013. Sirup. Jakarta.

Dalimartha, S. 2000. Atlas Tumbuhan ObatIndonesia. Jilid II. PT. Trubus Agriwidya. Jakarta.

Departemen Kesehatan Republik Indonesia. 2008. Materia Medika Indonesia. Cetakan Kelima. Departemen Kesehatan Republik Indonesia. Jakarta.

Djamil, R. dan Wijiastuti E. 2015. Penapisan Fitokimia, Uji Aktivita sekstrak Metanol Herba Seledri, Batang/Daun Ashitaba dan Daun Petroseli (Apiaceae). Dipresentasikan pada rakernas \& PITI AI Universitas Pancasila.Jakarta.
Goldsmith, L. A. dan MerkelC. M. 2001. Sucralose. Di dalam: Nabors LOB, editor. Alternative Sweetener, Ed ke3, New York.

Goodman, G. 2008. The Pharmacological Basis and Therapeutics. Penerbit Buku Kedokteran EGC. Bandung.

Gunawan, E. dan Simaremare E. S. 2016. Formulasi Sirup Antimalaria Ekstrak Kulit Batang Kayu Susu (Alstonia Scholaris L.) jurnal Pharmacy. 13 (1): 1-9.

Husen, R. W. M., Yamlean P. V. Y. dan Citraningtyas G. 2015. Formulasi Dan Evaluasi Sirup Ekstrak Daun Sidaguri (Sida rhombifolia L.). Pharmacon jurnal Ilmiah Farmasi - Unsrat. 4 (3): 134-138.

Kementerian Kesehatan Republik Indonesia. 2013. Riset Kesehatan Dasar. Badan Penelitian dan Pengembangan Kesehatan. Jakarta.

Liliana,W. 2011. Kajian Pembuatan Teh Herbal dari Seledri (Apium graveolens L.). Skripsi. Fakultas Pertanian. IPB. Bogor.

Manitto, P. 1981. Biosynthesis of Natural Products. Ellis Horwood Limited Publisher, Chicester, Ingris.

Masruhen. 2000. Perbandingan Kadar Flavonoid dan Daya Antihipertensi Antara Sari Etanol 50\% Daun Seledri (Apium graveolens L) Dan Biji Seledri Terhadap Tekanan Darah Sistemik Kucing Dianastesi. Skripsi. Fakultas Farmasi. UGM. Yogyakarta.

Muchtadi, D. dan Wijaya, C. H. 1996. Makanan Fungsional: Pengenalan dan 
Perancangan. Hand-Out Kursus Singkat Makanan Fungsional dan Keamanan Pangan. PAU Pangan dan Gizi. UGM. Yogyakarta.

Nadinah. 2008. Kinetika Inhibisi Ekstrak Etanol Seledri (Apium graveolens L.) dan Fraksinya Terhadap Enzim Xantin Oksidase Serta Penentuan Senyawa Aktifnya. Tesis. Sekolah Pascasarjana, IPB. Bogor.

Palupi, M. R. dan Widyaningsih, T. D. 2015. Pembuatan Minuman Fungsional Liang Teh Daun Salam (Eugenia polyantha) dengan Penambahan Filtrat Jahe dan Filtrat Kayu Secang. Jurnal Pangan dan Agroindustri.. 3(4): 1458-1464.

Rosita, I. I., Munisa,A. N., Kalsum, A.U. dan Rahmawati, A. 2014. Praktikum Kimia Fisika II Viskositas. Universitas Islam Negeri Syarif Hidayatullah.Jakarta.

Saragih, R. 2014. Uji Kesukaan Panelis Pada Teh Daun Torbagun. E-Jurnal Widya Kesehatan dan Lingkungan. 1 (1): 46-52.

Sayuti, N. A. 2015. Respon rasa campuran ekstrak seledri (Apium graveolens L.) dan ekstrak asam jawa (Tamarindus indica) dalam sediaan serbuk effervescent. Jurnal farmasi indonesia. 12 (2): 114-126.

Siswandono dan Soekardjo, B., 2000, Kimia Medisinal, Edisi 2, 228-232, 234, 239, Airlangga University Press, Surabaya.

Soewito. 1991. Bercocok Tanam Seledri. Titik Terang. Jakarta.
Sumaenda, L. (2011). Analisis Kandungan Klorofil Daun Mangga (Mangifera Indica L.) Pada Tingkat Perkembangan Daun Yang Berbeda. Bioslogos. 1 (1): 20-24.

Syahputra, A. R. dan Suhartini M. 2013. Peningkatkan Stabilitas Viskositas Pelumas Hidrolik Dari Kopolimer Lateks Karet Alam-Stirena. Bionatura-Jurnal Ilmu-ilmu Hayati dan Fisik. 15 (1):60-64.

Syamsuhidayat dan Hutapea, J.R., 1991, Inventaris Tanaman Obat Indonesia, 305-306, Departemen Kesehatan Republik Indonesia, Badan Penelitian dan Pengembangan Kesehatan, Jakarata.

Tedjasukmana, P. 2012. Tata Laksana Hipertensi Departemen Kardiologi, RS Premier Jatinegara dan RS Grha Kedoya. Jakarta. Indonesia.

Tim Prima Tani. 2011. Petunjuk Teknis Budidaya Seledri. Balai Penelitian Tanaman Sayuran. Bandung.

Tiwari, P., Kumar B., Kaur M., Kaur G. \& Kaur H. (2011). A review: Phytochemical Screening and Extraction. Internationale Pharmaceutica Sciencia, 1(1): 98-106.

Wahdah dan Nurul. 2011. Menaklukkan Hipertensid an Diabetes (Mendeteksi, Mencegah dan Mengobati Dengan Cara Medis dan Herbal). Multi Press, Yogyakarta. 